\title{
TVT versus TVT-O for Minimally Invasive Surgical Correction of Stress Urinary Incontinence
}

\author{
Vicente Sola, Jack Pardo, Paolo Ricci, Enrique Guiloff, Humberto Chiang \\ Urogynecology Unit, Department of Obstetrics and Gynecology, and Department of Urology, \\ Las Condes Clinic, Santiago, Chile
}

\begin{abstract}
Objective: The present work describes our experience in surgical correction of stress urinary incontinence, comparing both the TVT and the TVT-O techniques.

Method: Between October 2001 and March 2004, 76 patients underwent the TVT procedure. Between January 2004 and January 2005, 98 surgical corrections of urinary incontinence were carried out using the TVT-O technique.

Results: Median operative time was 28 minutes for TVT and 7 minutes for TVT-O. Intraoperative complications for TVT occurred in 4 patients $(6.6 \%)$ : urinary bladder perforation in 3 patients $(5 \%, \mathrm{p}=0.0228)$ and parietal peritoneum perforation in 1 case $(1.6 \%)$. No intraoperative complications took place during TVT-O. Immediate postoperative complications: transient urinary retention in TVT, 2 cases $(2.6 \%)$ and overcorrection in TVT-O (1\%) which was readjusted within 24 hours. There were no late complications after TVT. There were 2 cases (2.04\%) with late complications in TVT-O. TVT and TVT-O resulted in correction of incontinence in $100 \%$ of the patients.

Conclusion: TVT and TVT-O are two effective techniques for the correction of stress urinary incontinence. TVT-O would seem to be a technique much easier to perform resulting in less intraoperative complications.
\end{abstract}

Key words: urinary incontinence, stress; suburethral sling; female; tensionless vaginal tapes; transobturator tapes Int Braz J Urol. 2007; 33: 246-53

\section{INTRODUCTION}

A number of techniques for the correction of stress urinary incontinence have been described through the years. In 1996, Ulmsten published the minimally invasive technique known as TVT (1). Many authors believe TVT should be considered the gold standard for surgical correction of stress urinary incontinence (2), by virtue of its efficiency featuring up to $81 \%$ and $16 \%$ complete and partial remission respectively (3). Nevertheless, the technique entails the disadvantage of requiring intraoperative cystoscopy, and consequently it is not free of risks such as bladder, urinary tract and intestinal injury among others (4-7). In 2001, while in search of a simplified version of the procedure, Delorme (8-10) described the TOT technique (trans-obturator-tape). The main advantages of such technique are more anatomical position of the tape than with TVT, the fact that needles do not pass through the retropubic space, it entails less operative blood loss, do not involve abdominal incisions, is associated with a decreased risk of urinary bladder and 
intestinal injuries and does not require cystoscopy. Thus, TOT merged as an easier to perform and faster to achieve surgical technique when compared to TVT (11).

In 2003, Jean de Leval during an attempt to further simplify the procedure, described TVT-O (12). The TVT-O procedure is even closer to the concept of minimally invasive surgery than its predecessors TVT and TOT. Dissection of the anterior vaginal wall involves only one centimeter; the dissection of the paraurethral space is performed with fine scissors; the use of a winged bendable guide helps in the introduction of the needle; needles pass through only once and are withdrawn from the inner side of a protective plastic sheath; cystoscopy is not needed. As well as in the case of other kinds of TOT, the efficacy of such procedure should be further assessed in the long term (13). Undoubtedly, techniques involving polypropylene mesh tape within the medial urethra should be considered as first choice for SUI $(14,15)$.

The present work describes and compares our experience with TVT and TVT-O techniques in surgical therapy of urinary incontinence.

\section{PATIENTS AND METHODS}

Between October 2001 and March 2004, 76 patients underwent a surgical procedure with the classic TVT technique (1) at the Urogynecology and Vaginal Surgery Unit, Department of Obstetrics and Gynecology, of Las Condes Clinic. When we got to know the new technique TVT-O we decided to initiate and to compare them in our surgery experiences.

Between April 2004 and January 2005, 98 surgical corrections of urinary incontinence were carried out through the TVT-O technique (12).

Used TVT and TVT-O are system of Johnson \& Johnson Companies.

The data obtained for both surgical techniques were pooled in previously designed databases, for prospective follow-up.

For patients undergoing TVT, the median age was 53 years (range: 35 to 72 ), the median body weight was $64.8 \mathrm{~kg}$ (range: 50 to $90 \mathrm{~kg}$ ), the BMI was 27.6 (range: 23 to 32 ), and vaginal parity was 2 (range: 2 to 5 deliveries).

For patients undergoing the TVT-O procedure, the median age was 54 years (range: 38 to 74 ), body weight ranged between 53 and $82 \mathrm{~kg}$ (median $65 \mathrm{~kg}$ ), the BMI was 27.5 (range: 23 to 33 ), and vaginal parity was 2.6 (range: 0 to 5), Table-1. All patients underwent the urodynamics test in order to classify in preoperative time the type of urinary incontinence (according to the classification ICS 1999), which evidenced the following in patients scheduled for TVT: Type II SUI in $71(93 \%)$ patients (including 22 cases of mixed incontinence) and type III SUI or intrinsic sphincter deficit in 5 cases (7\%).

In patients scheduled for TVT-O, type II SUI was found in 91 (93\%) cases (including 9 cases of mixed incontinence), type III SUI was found in 4 cases (4\%) and type 0 SUI was evidenced in 3 cases (3\%), Table-2.

Table 1 - Comparison for study patients.

\begin{tabular}{lll}
\hline & \multicolumn{1}{c}{ TVT } & \multicolumn{1}{c}{ TVT-O } \\
\hline Number of patients & 76 cases & 98 cases \\
Months after surgery & $10 / 2001$ to $03 / 2004$ & $04 / 2004$ to $01 / 2005$ \\
Median age ( p Value $\left.0.263 \mathrm{~ns}^{*}\right)$ & 53 & 54 \\
Age range & 35 to $72(\mathrm{SD}=9.36)$ & 38 to $74(\mathrm{SD}=8.06)$ \\
Body weight $\left(\mathrm{p}\right.$ Value $\left.0.971 \mathrm{~ns}^{*}\right)$ & $64.8(\mathrm{SD}=8.25)$ & $65(\mathrm{SD}=8.03)$ \\
Body weight range & 50 to 90 & 53 to 92 \\
Body mass index & 27.6 & 27.5 \\
Vaginal parity & $2(0$ to 5$)$ & $2.6(0$ to5) \\
\hline
\end{tabular}

Comparison body weight and age, non-significant difference ( $n s, p>0.05)$ as for Student t test $(*)$. 
Table 2 - Comparison of the urodynamic test results. Urodynamic test performed before surgical correction in order to classify urinary incontinence.

\begin{tabular}{lcc}
\hline & TVT & TVT-O \\
\hline Type 0 SUI & 0 & $3(3 \%)$ \\
Type I SUI & 0 & 0 \\
Type II SUI & $71(93 \%)$ & $91(93 \%)$ \\
Type III SUI & $5(7 \%)$ & $4(4 \%)$ \\
Total & 76 & 98 \\
\hline
\end{tabular}

Urodynamic classification, ICS 1999. SUI = stress urinary incontinence.

There was a gynecological surgical procedure associated to the procedure for correction of urinary incontinence in 61 cases $(80.3 \%)$ for TVT and in 78 cases $(79.6 \%)$ for TVT-O. The gynecological surgical procedure took place in all cases during the period after TVT or TVT-O.

All these procedures were initially carried out under regional anesthesia, while in those cases requiring laparoscopy, additional general anesthesia was used.

Only TVT cases were implemented with intraoperative videocystoscopy.

The Foley catheter was removed only once the TVT or TVT-O procedure was completed, and after completing 24 hours of the preoperative period in those cases involving complementary surgery.

One simple intravenous dose of $2 \mathrm{~g}$ Cephazoline was used as prophylactic antibiotic therapy.

Rofecoxib 50 mg per os was administered one hour prior surgery as analgesia for TVT alone or in association with other surgical procedures, with further oral monodose every 24 hours.

The same dosing scheme was used for analgesia in patients undergoing TVT-O, since November 2004, replacing Rofecoxib for Valdecoxib $40 \mathrm{mg}$ following the same above-mentioned prescription.

All patients received information prior to surgery, which included details about the procedure, TVT or TVT-O respectively, and concerning the concomitant surgical procedure when indicated. All patients signed an informed consent.
All patients were controlled in an outpatient basis between 7 and 14 days and 3 and 6 months after the procedure. Telephone communication was maintained when needed.

Both patient populations displayed a normal distribution upon comparison. The student " $t$ " test for continuous parametric variables was used. The statistical analysis was carried out though the use of Excel (Microsoft Corporation) and Statview (SAS Institute, Cary, NC).

\section{RESULTS}

There were no significant differences between both groups upon comparing age and body weight.

\section{Association to Additional Gynecological Surgery}

In the TVT group there were 21 cases with two additional surgical procedures (34\%) and 40 cases with one additional surgical procedure (66\%). Among the TVT-O treated patients there was one additional surgical procedure in 66 patients (67\%), two in 26 patients $(27 \%)$ and three in 6 patients $(6 \%)$. Thirty cases required laparoscopic surgery $(31 \%)$.

As for TVT, vaginal plasty was the most commonly associated surgery, followed by laparoscopic hysterectomy, vaginal hysterectomy, laparoscopically assisted vaginal hysterectomy, laparoscopic tubal sterilization, Gargiulo's operation, adnexectomy and trachelectomy.

For TVT-O, the most commonly associated additional surgical procedure was vaginal plasty, followed by vaginal hysterectomy, laparoscopic hysterectomy, laparoscopic tubal sterilization and partial vulvectomy.

\section{Operative Time}

Measured from the opening to the closing of the vaginal mucosa):

Median operative time for TVT was 28 minutes (range between 20 and 48 minutes), while for TVT-O it was 7 minutes, with a range between 4 and 15 minutes. 


\section{Intraoperative Complications}

Among patients treated with TVT, intraoperative complications occurred in 4 cases $(6.6 \%)$. Complications were: bladder perforation in 3 cases $(5 \%)$ and parietal peritoneum in 1 case $(1.6 \%)$. Complications were due to the TVT needle insertion procedure, and were not related to the additional gynecological surgical procedure. Bladder perforation cases involved the lateral anatomical bladder area, and the location was corroborated with intraoperative cystoscopy. The needle was reinserted and the procedure was completed easily. A Foley catheter was placed for 4 days in one case and for 2 days in the remaining two cases. All patients underwent complete recovery, with no further complications. No additional interventions were needed in the case of parietal peritoneum perforation, in which we observed it like a finding when we made a laparoscopic surgery after anti-incontinence procedure.

TVT-O treated patients did not experience complications during the operative act. There was no bladder no urinary tract injuries (Table-3).

For both surgical techniques, intraoperative blood loss was scarce (less than $80 \mathrm{~mL}$ ).

\section{Immediate Postoperative Complications (up to 7 days)}

During the immediate postoperative period, among TVT treated patients, there were two cases of dysfunctional voiding ( 2 out of $76 ; 2.6 \%$ ), due to transient urinary retention. Both cases recovered after voiding through a Nelaton catheter in one occasion, with no need of further interventions. Both cases did not have associated surgery.

There were complications in one case (1 out of $98 ; 1.02 \%$ ), consisting of urinary retention due to overcorrection. The case required surgical correction at the operating room within 24 hours of the first surgery. The sutures of the mucosa of the anterior vaginal wall were removed $(1 \mathrm{~cm})$, and the tape was adjusted by means of traction with Kelly clamps between the urethra and the polypropylene mesh. The latter consisted of TVT-O associated with posterior colpoperineoplasty.

No hematomas or infections of the operative area were observed in any of the cases (Table-4).

\section{Analgesia}

There was no need for additional pharmacological therapy to the initially designed scheme for the

Table 3 - Comparison of intraoperative complications.

\begin{tabular}{llll}
\hline Complication & TVT & TVT-O & p Value \\
\hline Bladder perforation & $3(5 \%)$ & 0 & $0.0228(\mathrm{~s})$ \\
Parietal peritoneum perforation & $1(1.6 \%)$ & 0 & $0.5(\mathrm{~ns})$ \\
Total & $4(6.6 \%)$ & 0 & $0.0102(\mathrm{~s})$ \\
\hline
\end{tabular}

$s=$ significant difference $; n s=$ non-significant difference .

Table 4 - Comparison of immediate postoperative complications.

\begin{tabular}{llll}
\hline Complication & TVT & TVT-O & p Value \\
\hline Transient urinary retention & $2(2.6 \%)$ & 0 & $0.078(\mathrm{~ns})$ \\
Urinary retention requiring correction & 0 & $1(1.2 \%)$ & $0.1611(\mathrm{~ns})$ \\
Hematoma & 0 & 0 & $0.5(\mathrm{~ns})$ \\
Surgical wound infection & 0 & 0 & $0.5(\mathrm{~ns})$ \\
Total & $2(2.6 \%)$ & $1(1.02 \%)$ & $0.2206(\mathrm{~ns})$ \\
\hline
\end{tabular}

ns = non-significant difference. 
management of postoperative pain, since patients reported an adequate degree of pain control in all cases.

\section{Ambulation and Discharge}

For both approaches, all patients were asked to be up immediately after the loss of the effect of anesthetics. Food intake was resumed between 2 and 4 hours after surgery.

Discharge home occurred in both TVT and TVT-O unassociated with additional surgeries, after confirming a second spontaneous micturition. The median length of hospital stay was 48 hours for TVT and 12 hours for TVT-O.

For both approaches, in those cases associated with anterior or posterior colpoperineoplasty, discharge occurred at 24 hours. In those cases associated to hysterectomy, discharge occurred after 48 hours.

\section{Late Postoperative Period Complications (more than 1 week)}

There were no late complications for TVT, while there were late complications in 2 cases among TVT-O patients ( 2 out of $98 ; 2.04 \%$ ).

The first case consisted of polypropylene mesh tape erosion into the mucosa of the anterior vaginal wall, measuring $1 \mathrm{~cm}^{2}$, which was evidenced 6 weeks after surgery. The complication required sectioning the tape at the operating room, a procedure resulting free of complications. Such case had needed TVT-O associated with anterior and posterior colpoperineoplasty.

The second case consisted of a urinary retention occurring 11 days after surgery, it was of sudden onset. Urinary infection was ruled out and the retention corroborated to and evacuated with an in- termittent Nelaton catheter. Both sutures were removed from the mucosa of the anterior vaginal wall with local anesthesia (lidocaine) in an outpatient basis, and the position of the tape was adjusted through traction with scissors. The latter case was a TVT-O procedure associated with labioplasty. There were no new retention episodes and continence remained normal. There was no fistula formation in any of the cases (Table-5).

\section{Resolution of Urinary Incontinence}

Urinary incontinence was successfully corrected in $100 \%$ of TVT cases, including those with mixed incontinence. In 73 cases (96\%) there was cure (the incontinence absence after surgery was considered cure), while in the remaining $3(4 \%)$ the cure was partial or improvement (incontinence urinary episodes less than once every two weeks). There were no failures related to the technique.

Correction of the urinary incontinence was successful in all 98 patients (100\%) including those with immediate and late postoperative complications. Among patients with type II SUI, two cases presented de novo urge incontinence, which resolved spontaneously 30 and 45 days later respectively. Among those cases with mixed urinary incontinence ( 9 cases), only one patient remained with micturition urge, therefore she was treated with Detrusitol (Tolterodine) with a complete response to therapy.

Cases of fault were not observed (urinary incontinence episodes more of one per week), Table6 . The general comparison between TVT and TVT$\mathrm{O}$ is shown on Table-7.

All patients were followed in compliance with the protocol, which is still under observance in 6 TVT$\mathrm{O}$ cases.

Table 5 - Comparison of late postoperative complications (more than one week).

\begin{tabular}{lccc}
\hline Complication & TVT & TVT-O & p Value \\
\hline Tape exposition & 0 & $1(1.02 \%)$ & $0.1562(\mathrm{~ns})$ \\
Urinary retention requiring correction & 0 & $1(1.02 \%)$ & $0.1562(\mathrm{~ns})$ \\
Total & 0 & $2(2.04 \%)$ & $0.0764(\mathrm{~ns})$ \\
\hline
\end{tabular}

ns $=$ non-significant difference. 
Table 6 - Comparison of resolution of urinary incontinence between both techniques.

\begin{tabular}{lccc}
\hline Resolution of SUI & TVT & TVT-O & p Value \\
\hline Total & $73(96 \%)$ & $98(100 \%)$ & $3.84(\mathrm{~s})$ \\
Partial & $3(4 \%)$ & 0 & \\
\hline
\end{tabular}

$s=$ significant difference.

\section{COMMENTS}

A great number of techniques have been described for the correction of stress urinary incontinence. Lately, tension-free tape techniques, introduced in 1996 with TVT, have undergone a significant development.

The TVT-O approach is easier to perform, by virtue of the fact it does not require intraoperative cystoscopy. Needles are passed from "outside to inside", and thus remain far from the bladder and the urinary tract, consequently decreasing the risk of an eventual bladder perforation ( $\mathrm{p}=0.00228$ : statistically significant). Furthermore, the use of guides enables an easy introduction towards the obturators. All the above mentioned has resulted in the absence of intraoperative complications across our experience with TVT-O compared to the TVT approach (statistically significant difference).
When comparing postoperative complications in our experience in both procedures was low, the difference between both techniques in our experience is remarkable. Complications in TVT-treated patients were two cases of transient urinary retention during the immediate postoperative period, and were treated with Nelaton catheter evacuation, not requiring additional interventions. In contrast, among TVT-O-treated patients the complication was an overcorrection during the immediate postoperative period, which required correction. For the same technique, during the late postoperative period, there was one case of erosion to the anterior vaginal wall due to tape exposition, and a case of urinary retention after the 11th postoperative day, which required tape adjustment. Taking into consideration this last case, we started leaving a looser tape under the urethra, and obtained the same results for resolution of the incontinence, preventing thus such complication from occurring again.

Both techniques are effective in correcting stress urinary incontinence, with $100 \%$ success rate. For TVT, a partial cure or improvement occurred only in $4 \%$ of the cases. When comparing only cure rates there is a statistically significant difference between TVT and TVT-O, favoring TVT-O.

In the present when we asked to these patients (TVT and TVT-O) about quality of life, they respond that it has improved remarkably. Nevertheless, we have initiated new protocols of pursuit and we continued adding new patients to register if the cure rates stay in the time.

Table 7 - General comparison between TVT and TVT-O.

\begin{tabular}{lll}
\hline Comparison & TVT & TVT-O \\
\hline Operative time (median) & $28 \mathrm{~min}$ & $7 \mathrm{~min}$ \\
Range of operative time & 20 to $48 \mathrm{~min}$ & 4 to $15 \mathrm{~min}$ \\
Time for ambulating & 2 to 4 hours & 2 to 4 hours \\
Length of hospital stay & 48 hours & 12 hours \\
Resolution of SUI & $100 \%$ & $100 \%$ \\
Intraoperative complications $(\mathrm{p}=0.0102, \mathrm{~s})$ & $4(6.6 \%)$ & 0 \\
Immediate postoperative complications $(\mathrm{p}=0.2206 \mathrm{~ns})$ & $2(2.6 \%)$ & $1(1.02 \%)$ \\
Late postoperative complications $(\mathrm{p}=0.0764, \mathrm{~ns})$ & 0 & $2(2.04 \%)$ \\
\hline
\end{tabular}

$s=$ significant difference $; n s=$ non-significant difference. 


\section{CONFLICT OF INTEREST}

None declared.

\section{REFERENCES}

1. Ulmsten U, Henriksson L, Johnson P, Varhos G: An ambulatory surgical procedure under local anesthesia for treatment of female urinary incontinence. Int Urogynecol J Pelvic Floor Dysfunct. 1996; 7: 81-5; discussion 85-6.

2. Debodinance P, Delporte P, Engrand JB, Boulogne M: Tension-free vaginal tape (TVT) in the treatment of urinary stress incontinence: 3 years experience involving 256 operations. Eur J Obstet Gynecol Reprod Biol. 2002; 105: 49-58.

3. Nilsson GC, Rezapour M, Falconer C: 7 year follow-up on the Tension-free Vaginal Tape (TVT) procedure. Int Urogynecol J Pelvic Floor Dysfunct. 2003; IUGA Abst \#116.

4. Ulmsten U, Falconer C, Johnson P, Jomaa M, Lanner L, Nilsson CG, wt al.: A multicenter study of tension-free vaginal tape (TVT) for surgical treatment of stress urinary incontinence. Int Urogynecol J Pelvic Floor Dysfunct. 1998; 9: 210-3.

5. Allahdin S, McKinley C, Mahmood TA, Lyth D: Tension-free vaginal tape: 162 cases in a district general hospital. J Obstet Gynaecol. 2004; 24: 539-41.

6. Abouassaly R, Steinberg JR, Lemieux M, Marois C, Gilchrist LI, Bourque JL, et al.: Complications of tension-free vaginal tape surgery: a multi-institutional review. BJU Int. 2004; 94: 110-3.

7. Jimenez Calvo J, Hualde Alfaro A, Santiago Gonzalez de Garibay A, Pinos Paul M, Jimenez Aristu J,
Montesino Semper M, et al.: TVT: three years of experience. Actas Urol Esp. 2004; 28: 13-20.

8. Delorme E: Transobturator urethral suspension: miniinvasive procedure in the treatment of stress urinary incontinence in women. Prog Urol. 2001; 11: 1306-13.

9. Delorme E, Droupy S, de Tayrac R, Delmas V: Transobturator tape (Uratape). A new minimally invasive method in the treatment of urinary incontinence in women. Prog Urol. 2003; 13: 656-9.

10. Costa P, Grise P, Droupy S, Monneins F, Assenmacher C, Ballanger P, et al.: Surgical treatment of female stress urinary incontinence with a trans-obturator-tape (T.O.T.) Uratape: short term results of a prospective multicentric study. Eur Urol. 2004; 46: 102-6; discussion 106-7.

11. Mellier G, Benayed B, Bretones S, Pasquier JC: Suburethral tape via the obturator route: is the TOT a simplification of the TVT? Int Urogynecol J Pelvic Floor Dysfunct. 2004; 15: 227-32.

12. de Leval J: Novel surgical technique for the treatment of female stress urinary incontinence: transobturator vaginal tape inside-out. Eur Urol. 2003; 44: 724-30.

13. Costa P, Delmas V: Trans-obturator-tape procedure"inside out or outside in": current concepts and evidence base. Curr Opin Urol. 2004; 14: 313-5.

14. Rechberger T, Wrobel A, Adamiak A, Skomra D, Korobowicz E, Tomaszewski J, et al.: Tissue reaction to polypropylene mono-or multi-filament tapes used in surgical techniques of stress urinary incontinence treatment. Ginekol Pol. 2003; 74: 1008-13.

15. Bemelmans BL, Chapple CR: Are slings now the gold standard treatment for the management of female urinary stress incontinence and if so which technique? Curr Opin Urol. 2003; 13: 301-7.
Accepted after revision:

September 30, 2006

\section{Correspondence address:}

Dr. Vicente Solà Dalenz

Department of Obstetrics and Gynecology

Las Condes Clinic, Lo Fontecilla 441

Las Condes, Santiago, Chile.

Fax: +5622104195

E-mail:vsola@vtr.net 


\section{EDITORIAL COMMENT}

The authors report on their experience with TVT and TVT-O in the surgical treatment of female stress urinary incontinence. The two study populations were relatively homogenous with regards to number, age, parity, and BMI. The authors detected very high rates of surgical cure with both techniques but noted a comparatively distinct ease of use with the TVT-O.

The authors should be commended for adding to the world's literature their experience with the relatively new TVT-O technique. Highlights that they have noted include the low rate of perioperative complications including voiding dysfunction (urinary urge incontinence and urinary retention) and vaginal tape erosion. It is hoped that in 3-5 years the authors consider revisiting the study population and report on the durability rates of this operation as well as potential appearance of any late complications.

Dr. Steven P. Petrou Associate Professor of Urology Chief of Surgery, St. Luke's Hospital Associate Dean, Mayo School of Graduate Medical Education Jacksonville, Florida, USA E-mail: petrou.steven@mayo.edu 